
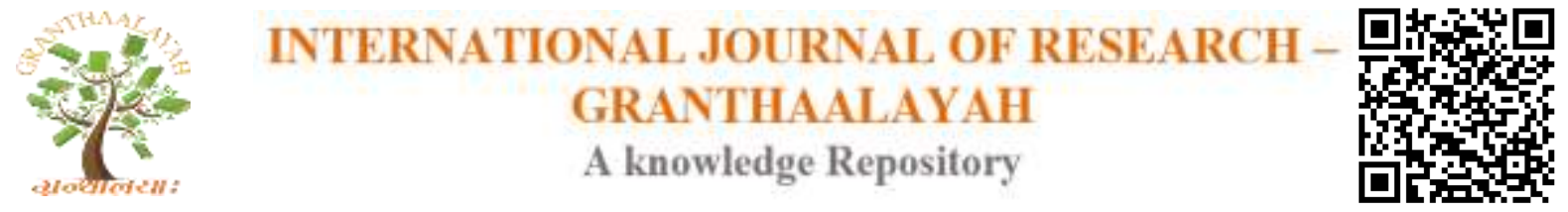

Social

\title{
THE RELATIONSHIP BETWEEN WATER, POVERTY AND HEALTH EXPENDITURE: AN ANALYSIS
}

\author{
Mangal Sing Kro *1 \\ ${ }^{*}$ Gauhati University, India
}

\begin{abstract}
Even though the human being cannot live without water it has the negative effect on human health too. Its effect depends on the quality of water which human beings drink. The contaminated water used by human beings may degrade human health with the help of some toxic substances, like, fluoride, arsenic, mercury, lead etc. The poor people are prone to suffer from these toxic substances although they, generally, cannot afford for the water of good quality for drinking and washing. Moreover, there is a lot of water-washed diseases, water based diseases, water born diseases etc. which affect human health. These diseases and toxic substances increase health expenditure of the people. Therefore, contaminated water forces the poor people to stay in the vicious circle of poverty if they use it. This paper will analyze water, poverty and health expenditure nexus.
\end{abstract}

Keywords: Disease; Health Expenditure; Poverty; Water.

Cite This Article: Mangal Sing Kro. (2017). "THE RELATIONSHIP BETWEEN WATER, POVERTY AND HEALTH EXPENDITURE: AN ANALYSIS." International Journal of Research - Granthaalayah, 5(7), 214-218. 10.29121/granthaalayah.v5.i7.2017.2125.

\section{Introduction}

Poverty is generally defined as the people those who are unable to afford for their basic needs. The basic needs are like food, shelter, clothing, water, and sanitation, health and education. Various methods have been given by the economists to measure the poverty, like Head Count Ratio, Poverty Gap, Foster-Greer-Thorbecke Index, Human Poverty Index etc. The World Bank has given the minimum norms for poverty based on the 2011 purchasing power parity (PPP) of the currency. Previously, it was pegged at $\$ 1.25$ a day but, now it has been revised to $\$ 1.90$ a day based on the average of the national poverty line of 15 poorest economies of the world. According to the World Bank report, $12.8 \%$ global populations are extremely poor. In 2012, more than $78.8 \%$ of extremely poor people lived in South Asia and Sub-Saharan Africa (The Hindu). Most of the poor people are living in rural area in all developing countries. These poor people are generally landless and small landholders and agriculture is the main source of their livelihood. Some of the poor people work as the carpenter, blacksmith, pottery, grocery, herders, milkman, and daily wage workers etc. Their main sources of water for drinking, washing, and 
cleaning are dug well, river, spring water, ponds etc. But due to the dearth of safe drinking water the water-borne diseases like cholera, dysentery, diarrheal disease, guinea worm disease etc., infects the poor people which ultimately increases their household expenditure for the disease treatment. Moreover, due to the lack of safe drinking water also increases financial burden which eventually leads to increase the dropout rate in schools, colleges among the poor. The contaminated water used by the poor people enhance the expenditure on health and it again pushes back to the cycle of poverty. In India, around 37.7 million populations are affected by waterborne diseases annually and 1.5 million children are estimated to die only of diarrhea (Khurana \& Sen).

\section{Objective of the Study}

1) To look into the water, poverty and health expenditure nexus.

2) To investigate the impact of contaminated water on human health.

\section{The Selected Existing Literature}

The human beings use water for multipurpose, like for drinking, washing, bathing, for agriculture, industries etc. But the use of contaminated water effect negatively on human beings. The contaminated water creates diseases that ultimately effect on human health as well as on its households expenditure. There is a number of water-washed diseases, water based diseases, water born diseases and water-related diseases. According to the World Health Organization (WHO) 2000, about 202 million people deaths per year for diarrheal disease only. Around 10,000 people die every day from water and sanitation related diseases and illnesses in the world and majority of them belong to developing countries (Abayawardana, S. \& Hussain, I., 2002). The payments on healthcare push a large number of families into poverty (Van Doorslaer et al, 2006). In the absence of insurance, all illness not only reduce welfare directly, it also increases the risk of impoverishment due to high treatment expenditures (Gupta, I.,2009).

\section{Methodology}

Good health is one of the components of human capital and the human capital is one of the factors for development. Therefore, weak health reduces not welfare only, rather it increases the financial burden of the households too. The safe drinking water and sanitation is one of the important factors to keep good health of the people. The dearth of safe drinking water may create a number of diseases which may drain the limited income of the poor people. This paper will analyze the interlinkage among water, poverty and health expenditure. The data used for analyzing are taken from secondary sources collecting from national and international reports, books, and journals as well as through my own observation.

\section{Water and Human Beings}

Life without water is impossible. It is used for drinking, washing, bathing, agriculture, industries etc. The food grains for human consumption come from agriculture and the agriculture is not possible without water. The agriculture is the main income source of the rural poor. In developing countries, due to lack of adequate irrigation facilities, natural rainwater is the main 
runner for harvesting. However in some area, basically, nearby forest area people manage water supply in their agriculture field by indigenous water management technique like making canal by the villagers on the small river. But, natural rain water is still playing a pivotal role in agriculture of developing countries. The natural rainwater used by poor farmers is shown in following figure 1.

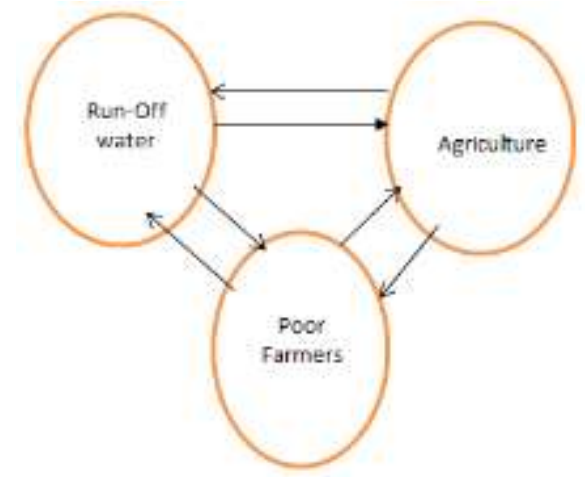

Figure 1: Use of run-off water in Agriculture field

In the fig.1, The poor farmers used runoff water in agriculture is shown by the upward extreme left side arrow in the figure, but the run-off water used in agriculture also provides other services such as, for cleaning, washing, etc., i.e., shown on left side downward arrow. The upper arrow indicates the run-off water used in agriculture and the lower arrow indicates stabilizing of the water table in the concerned area; the right side upward arrow indicates agriculture practiced by poor farmers and the extreme right side downward arrow depicts how agriculture supports poor farmers.

Even though human life is impossible without water, the contaminated water affects on human health. There are a lot of diseases that related to water. A few examples of water-related diseases are given in the table1.

Table 1: Water-related Diseases

\begin{tabular}{lll}
\hline S1.No. & Water-Related Diseases & Name of Diseases \\
\hline $\mathbf{1}$ & Water Borne Diseases & $\begin{array}{l}\text { Cholera, typhoid, amoebic and bacillary } \\
\text { dysentery and other diarrheal diseases. }\end{array}$ \\
$\mathbf{3}$ & Water Washed Diseases & $\begin{array}{l}\text { Scabies, trachoma and flea, lice and tick-borne } \\
\text { diseases. }\end{array}$ \\
$\mathbf{4}$ & Water based Diseases & $\begin{array}{l}\text { Dracunculiasis, schistosomiasis, and other } \\
\text { helminths. } \\
\text { Wengue, malaria, filariasis, onchocerciasis, } \\
\text { trypanosomiasis and yellow fever. }\end{array}$ \\
\hline
\end{tabular}

\section{Out of Pocket Expenditure on Health}

The contaminated water used by the people increases the financial burden of the household because the contaminated water or lack of safe drinking water creates a number of diseases. In the developing countries, like India out of pocket expenditure (OOP) on health is more than public expenditure. The expenditure on health out of their pocket by the poor people affects on 
their children education, food requirements etc. The World Bank has divided the economies into four groups according to 2009 GNI per capita using Atlas Method, such as Low Income (\$995 or less), Lower Middle Income (\$996-\$3945), Upper Middle Income (\$3946-\$12195) and High Income (\$12196 or more) and accordingly WHO has shown the Out-of-Pocket health expenditure with respect to this different groups.

Table 2: Out-of-Pocket Health Expenditure, 2012

\begin{tabular}{llc}
\hline Sl.No. & Country Group & $\begin{array}{l}\text { Out-of-Pocket Health Expenditure as a } \\
\text { \% of Total Health Expenditure }\end{array}$ \\
\hline $\mathbf{1}$ & Low Income & 47.9 \\
$\mathbf{2}$ & Lower Middle Income & 53.4 \\
$\mathbf{3}$ & Upper Middle Income & 32.2 \\
$\mathbf{4}$ & High Income & 17.8 \\
\hline
\end{tabular}

Source: WHO, 2014 (Global Health Expenditure Database).

The table 2 shows that the out-of-pocket health expenditure is $47.9 \%, 53.4 \%, 32.2 \%$ and $17.8 \%$ in low income, lower middle income, upper middle income and high-income countries respectively. The out-of-pocket expenditure on health is lowest in high-income countries and it is highest in lower middle-income countries. In other words, out-of-pocket health expenditure is lowest in developed countries and it is very high in developing countries.

\section{Contaminated water, Diseases and Poverty's relationship}

Contaminated water is polluted water having foreign toxic substances, like arsenic, fluoride, mercury, lead etc. which is not fit for human consumption. Consumption such water affects on human health which ultimately reduces human welfare. But, unfortunately, millions of the people are still drinking this contaminated water which increases mortality and morbidity and reduces the longevity of the people. The consumption of such water increases households' expenditure too because of consumption of such water harm human health through different types of diseases, like cholera, malaria, diarrheal, polio, dengue etc. The relationship among contaminated water, diseases, and poverty is explained through the following figure 2.

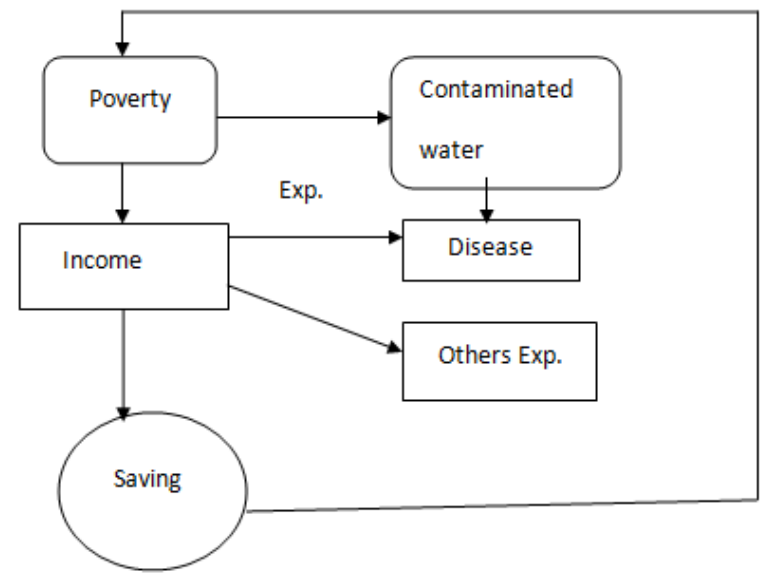

The lack of safe drinking water or contaminated water used by poor people forces them to stay in a poverty trap. The contaminated water creates diseases; as a result, a part of their income is expended for disease treatment. Although, the poor people mean low-income group, therefore, 
the income of the poor are expended on disease treatment and on other household expenditures. Generally, they have either zero or low saving or negative saving. The zero or low saving or negative saving means low capital formation like they cannot be able to afford for their children education and for physical capital. The low capital formation ultimately pulls back the poor people into the poverty trap.

\section{Conclusion and Policy Implication}

The diseases are one of the main factors for creating vicious circle poverty. These diseases are mainly come out from contaminated water. They add extra expenditure to the households' budget that leads to deficit budget of the poor families and deprives the children' education as well. This low capital formation (both human capital and physical capital) pulls back into the earlier position. Therefore, different steps can be taken to reduce diseases as well as the poverty.

i. The government should increase health expenditure out of its GDP so that out-of-pocket expenditure is reduced.

ii. The safe drinking water and sanitation facilities should be provided so that diseases and expenditure on diseases are reduced.

iii. Awareness, as well as health education, should be effectively provided through health workers.

iv. Nutritional education is also needed to mitigate diseases.

The out-of-pocket health expenditure of the poor people means non-fulfilment of other needs. Therefore, high out-of-pocket health expenditure, especially in developing countries, will impact on human capital formation. The low human capital formation will impact negatively on the economy. The public health expenditure only on diseases treatment is not the end of the government; it should give importance on other sides too, like health education, effective health awareness programme, nutritional education etc.

\section{References}

[1] Gupta, I. (2009). Out-of-pocket expenditure and poverty: Estimates from NSS 61 st round. Paper presented for consideration of the expert group on poverty, planning commission. Retrieved from http://planning commission.nic.in/reports/genrep/indrani.pdf.

[2] Gleick, P.H. (2002). Dirty water: Estimated deaths from water-related diseases 2000-2020.

[3] Von Doorslaer, E. et al (2006). Effect of payment for health care on poverty estimates in 11 countries in Asia: An analysis of household survey data.

[4] World Bank estimates show fall in India's Poverty Rate. Retrieved from http://www.thehindu.com/news/national/world-bank-estimates-show-fall-in-indias-povertyrate/article7727591.ece.

[5] Water aid. Drinking water quality in rural India: Issues and approaches. Retrieved from http://www.wateraid.org/ /media/Publications/drinking-water-quality-rural-india.pdf.

[6] Country Classification. Retrieved from http://go.worldbank.org/L547EEP5C0.

[7] Abayawardana, S. \& Hussain, I. (2002). Water, health and poverty linkages: A case study from Sri Lanka. Paper prepared for the Asian Development Bank Regional Consultation Workshop on Water and Poverty, Dhaka, Bangladesh.

\footnotetext{
*Corresponding author.

E-mail address: mangalkro@ gmail.com
} 